\title{
REVOLUCIÓN RUSA Y AMÉRICA LATINA: UNA PROMESA INCUMPLIDA*
}

\author{
Evguenia Fediakova \\ Universidad de Santiago
}

\begin{abstract}
RESUMEN: Este trabajo analiza la recepción que la Revolución Rusa tuvo por parte de intelectuales, partidos y movimientos sociales en América Latina. Ella generó una promesa utópica y de cariz religioso sobre la puesta en práctica de una nueva sociedad, sin injusticias ni oprimidos, ilusión que, si bien rara vez se enfrentó a la realidad de la URSS, sí sirvió de detonante para importantes movimientos políticos que el siglo XX conoció en este lado del mundo.
\end{abstract}

Palabras Clave: Revolución Rusa, Revolución de Octubre, URSS, Latinoamérica, partidos comunistas, intelectuales latinoamericanos.

\section{THE RUSSIAN REVOLUTION AND LATIN AMERICA: AN UNFULFILLED PROMISE}

ABstRACT: This paper analyses the reception given to the Russian Revolution by intellectuals, parties and social movements in Latin America. The Revolution promised a utopia of religious complexion in the form of a new society free of injustice and oppression, and although this promise was rarely compared to the actual situation in the USSR, it did serve as a trigger for major political movements on this side of the world during the twentieth century.

Keywords: Russian Revolution, October Revolution, USSR, Latin America, communist parties, Latin American intellectuals.

Evguenia Fediakova. PhD en ciencias políticas por la Academia de Ciencias de Rusia y máster en historia por la Universidad Lomonosov. Investigadora del Instituto de Estudios Avanzados de la Universidad de Santiago. Email: evguenia.fediakova@usach.cl.

* Este ensayo fue preparado con ocasión del seminario "Revolución Rusa en América Latina y Chile", celebrado en el Centro de Estudios Públicos, el 17 de octubre de 2017. 
Rusia de Lenin es un símbolo. Canaliza pasiones más que ideas.

François Furet

\section{INTRODUCCIÓN}

E ric Hobsbawm sostuvo que "la Revolución Rusa, o la revolución bolchevique, ha sido un acontecimiento tan crucial para este siglo (el XX), ${ }^{1}$ como lo era la Revolución Francesa del 1789 para el devenir del siglo XIX" y cuyo impacto ha sido mucho más profundo y duradero que el de Francia (Hobsbawm 2007, 63).

Cuando vivía en la Unión Soviética, observando las majestuosas celebraciones, con las cuales cada 7 de noviembre ${ }^{2}$ se festejaban los aniversarios de la Gran Revolución de Octubre, siempre me preguntaba con qué magnitud se iba a celebrar el centenario de la revolución. La URSS desapareció, la ideología comunista en Rusia quedó marginada, y hoy, salvo el mundo académico y algunos medios de comunicación, en Rusia reina el silencio casi total sobre este "principal acontecimiento del siglo XX", como lo sostenía antaño la propaganda oficial soviética. Parece que el mundo entero expresa más interés y le otorga más importancia a la memoria del centenario de la revolución que el que le dedica la propia sociedad rusa.

Y eso es comprensible. Las primeras generaciones de los soviéticos vivían, se sacrificaban, construían y morían por la revolución socialista mundial. Sus hijos vivían, se sacrificaban, morían para defender y salvar al "primer país socialista del mundo" (y a la democracia europea también) en 1941-1945. Sus nietos vieron la falsedad, la hipocresía, la decadencia y, al final, el derrumbe del comunismo y de la Unión Soviética desde adentro. La magia y el mito de la Gran Revolución murieron.

No obstante, desde afuera, la mayoría de los millones de "humillados y ofendidos" del mundo que se sintieron identificados con la causa bolchevique no conocía las realidades del socialismo real de la URSS. Ellos concebían a la Revolución de Octubre de una manera emocional, pasional, imaginaria; es decir, creyente. Para ellos, la Revolución Rusa era un acto de fe que iba mucho más allá de la creación

\footnotetext{
${ }^{1}$ El paréntesis aclaratorio es mío.

${ }^{2}$ En cierta ocasión, un analista irónico observó: "En la Unión Soviética nada es cierto: hasta la Revolución de Octubre se celebra el mes de noviembre".
} 
de un Partido Comunista, era mucho más que las cambiantes políticas del Komintern, ${ }^{3}$ era mucho más que la política exterior de la Unión Soviética durante la Guerra Fría. Creemos que el mayor impacto que provocó la Revolución de Octubre no consistió necesariamente en los cambios económicos, sociales o institucionales que ella realizó, sino en las percepciones espirituales, culturales y a veces irracionales que ella provocó; es decir, en cómo incidió en la esfera del imaginario colectivo.

El objetivo de este ensayo es justamente demostrar el impacto emocional y cultural que provocó la Revolución de Octubre de 1917 en las sociedades y mentalidades latinoamericanas. No es nuestro interés analizar en este espacio distintas etapas del funcionamiento del Komintern y el significado que tenía cada una de éstas para el movimiento comunista en Latinoamérica. ${ }^{4}$ Tampoco vamos a analizar las facetas de la política exterior de la URSS durante la Guerra Fría en el Cono Sur y el Caribe. Creemos que esto ya no es la Revolución en sí misma. Ya eran las políticas de un Estado que en su acción internacional tenía un doble lenguaje: el de Estado-nacional que defendía sus propios intereses y el del líder de la revolución mundial. En cambio, quisiéramos observar cómo la llegada de la Revolución cambió la percepción de la realidad de un contexto nacional específico, la percepción de un trabajador latinoamericano sobre sí mismo, la autosensación que elaboró la intelectualidad de América Latina frente al desafío de responder por su compromiso con la justicia, fraternidad y solidaridad que le despertó la Revolución Rusa.

Históricamente, el concepto de imaginario colectivo se ha vinculado con los campos de estudio de la psicología, literatura, historia del arte y la religión. Se refiere a la esfera de los sueños, quimeras y "pensamientos falsos" (ilusiones, como diría François Furet). El siglo XX, período de grandes conflictos ideológicos y sociales, convirtió al imaginario en un campo de estudio independiente, otorgándole la importante función de legitimar el sistema de poder y ser campo de lo político (Bazco 1984, 12). El siglo XX es también la etapa de la lucha ideológica y propagandística, la guerra de las ideas, de construcción de utopías

${ }^{3}$ Se conoce como Komintern a la III Internacional Comunista, de 1919 (N. del E.).

${ }^{4}$ Sobre este tema, véanse los trabajos de A. Varas (1991), O. Ulianova y A. Riquelme (2005), entre otros. 
y de todas aquellas representaciones que, si bien nacen en nuestra imaginación, tienen la capacidad de afectar profundamente el mundo real.

Por esta razón, el imaginario está correlacionado con la identidad colectiva. Es una manera de definir la relación con los "otros", de formar imágenes de amigos y enemigos, de conservar y modelar los recuerdos pasados y proyectar los temores y esperanzas hacia el futuro. De esta manera, el imaginario aparece como una de las fuerzas reguladoras de la vida colectiva, el lugar de los conflictos sociales y una de las cuestiones que están en juego en estos conflictos (Bazco 1984, 28). Al mismo tiempo, el imaginario colectivo constituye la obra y el instrumento de nuestra conciencia y comportamiento: por una parte, es el resultado de la formación cultural y herencia identitaria de la sociedad, $y$, por otra, representa el instrumento de elaboración de una actitud o de una política hacia las realidades alejadas de nosotros en el tiempo, en el espacio o en su representación física o cultural (Loyola y Rojas 2000, 109).

La imagen y el impacto de la Revolución de Octubre de 1917, efectivamente, estremecieron y transformaron a Rusia y a toda la humanidad. Por primera vez en la historia del mundo triunfó una fuerza que colocó como la prioridad de su proyecto político y social la idea de que "un ser humano no es menor que el otro" y que todos tenían los derechos económicos, sociales, políticos, culturales iguales, sin importar su procedencia ni raza. ${ }^{5}$ Tenemos que recordar que ésta no era la única revolución rusa del siglo, sino que la tercera y la más radical. Ésta culmina el período revolucionario comenzado por la revolución de 1905 (que dio a Rusia su primera constitución) y continuado por la revolución de febrero de 1917 (que acabó con la monarquía y prometió, sin cumplir, establecer la libertad, la paz y la democracia). Pero los bolcheviques, que triunfaron en octubre de 1917 con un programa mucho más prometedor, fueron quienes, por una parte, continuaron con las promesas de la libertad, la paz, repartición de la tierra para los campesinos, y, por la otra, ofrecieron los réditos del poder para los trabajadores, junto a justicia social, igualdad, fraternidad y respeto por la dignidad humana;

${ }^{5}$ Es importante recalcar que estamos hablando de imágenes y percepciones que proyectaba la Rusia soviética, y no del costo humano real que la sociedad rusa tuvo que pagar para implementar estas ideas mediante la violencia de la Revolución y la Guerra Civil que se dio entre 1918 y 1922. 
todo esto no solamente para Rusia, sino que para la clase trabajadora de todo el planeta. Es la razón por la cual la caída del gobierno provisional "burgués" provocó tanto entusiasmo y admiración entre los mineros de Gran Bretaña, los socialistas de Alemania, Francia y Hungría, los anarquistas de España, muchos intelectuales de Europa y de Rusia misma. Por primera vez en el siglo XX el mundo se dividió en dos órdenes: el antiguo capitalista burgués, por un lado, y el nuevo, joven y revolucionario y comunista, por el otro.

En América Latina, la Revolución de Octubre también fue recibida con euforia por unos, y con mucho temor, por otros. Antes de la Revolución, Latinoamérica y Rusia sabían muy poco la una de la otra. Los vínculos directos y contactos permanentes eran escasos en comparación con los de Europa. La lejanía entre el continente latinoamericano y el enigmático país euroasiático, lo hacía parecer casi inaccesible e inimaginable. La escasa información que llegaba al continente iberoamericano procedía de las notas de las agencias de prensa extranjeras o de los inmigrantes judíos, polacos, alemanes, rusos que llegaban a América desde Europa. Por cierto, en América Latina y el Caribe hacia 1917 ya existían agrupaciones anarquistas, anarco-sindicalistas, socialistas, primeras organizaciones obreras. Se conocían las obras de grandes escritores rusos como Tolstoi, Dostoievski y Chejov. Aparte de Marx y Engels, se leían y se estudiaban los trabajos de pensadores marxistas y anarquistas populistas, como Bakunin, Kropotkin y Plejánov. Pero estas obras se percibían también como provenientes de un mundo tan remoto, desconocido y extraño que parecía irreal. ${ }^{6} \mathrm{El}$ mundo ruso era un enigma, un mosaico incompleto de imágenes de un país que fue gobernado por un zarismo despótico y cruel, donde el pueblo, campesino, triste, místico y esclavo, expresaba su misteriosa alma en medio de enormes estepas blancas y frías en forma de exóticos ritos de la religión ortodoxa y las melancólicas melodías esteparias acompañadas por extraños gemidos de las balalaicas.

Tras estallar la Revolución de 1917, en América Latina se produjo el "descubrimiento de Rusia". Junto con seguir leyendo las noticias de la guerra, la sociedad latinoamericana fue deteniendo su mirada sobre el gobierno de los "maximalistas". La palabra "bolchevique" y su sig-

${ }^{6}$ Quizás con menor intensidad en México o Argentina, pero con mucho mayor intensidad en Cuba o en Chile. 
nificado no han sido aprendidos aún. Las páginas de la prensa de Chile, Cuba, Brasil, Argentina se llenaron con las noticias y reportajes sobre este gigantesco país incógnito y remecido por la revolución. Muy pronto la revolución bolchevique provocó gran apoyo, interés y conmoción entre los estudiantes universitarios de Argentina (durante el movimiento por la reforma de la universidad del 1918), los anarquistas y socialistas de Cuba y los obreros de Chile. Desde los primeros meses posteriores al triunfo del partido de Lenin, el diario chileno El Despertar de los Trabajadores se declaró como un aliado incondicional de la lucha de los comunistas rusos. En febrero del 1918, Luis Emilio Recabarren publicó:

Es el caso inequívoco que debemos declarar de qué lado quedamos: si con los maximalistas que derrumban con la acción (no con las palabras) el militarismo y el capitalismo... o preferimos marchar engañados al lado de la burguesía... Doy, sin vacilar, mi voto de adhesión a los maximalistas que inician el camino de la paz y de la abolición del régimen burgués, capitalista y bárbaro. ${ }^{7}$

José Alien, el futuro secretario general del Partido Comunista Mexicano, por esos días señaló:

Esto no es un experimento, no es un simple cambio en el gobierno, es una plena transformación de todo, y eso va a realizarse, porque la fuerza del proletariado ruso está en el apoyo de todos los trabajadores del mundo. (Citado por Korolev y Kudachkin 1986, 20)

El Manifiesto del año 1918, aprobado por el congreso constituyente del Partido Socialista Internacional (futuro Comunista) de Argentina, dijo:

Los bolcheviques de Rusia son la vanguardia del socialismo mundial, que colocaron los cimientos de una nueva sociedad humanitaria que no conoce los privilegios de casta y sociales, ni despotismo y guerras. (Citado por Korolev y Kudachkin 1986, 20)

En febrero de 1918, Rusia soviética recibió un emotivo y fraternal saludo desde el México revolucionado. Escribe Emiliano Zapata:

\footnotetext{
${ }^{7}$ El Despertar de los Trabajadores, 3 de febrero de 1918.
} 
Nosotros ganaríamos mucho y la causa de la justicia humana ganaría mucho si los pueblos de nuestra América y todas las naciones de la vieja Europa hubiesen entendido que la causa de México revolucionario y Rusia libre es la causa de toda la humanidad, son los objetivos sublimes de todos los oprimidos del mundo... Ambas revoluciones están dirigidas en contra de los que León Tolstoy llama el "gran crimen": en contra de la usurpación de la tierra que pertenecía a todos, igual como el agua y el aire, pero que a pesar de eso fue arrancada por un grupúsculo de poderosos con el apoyo de sus ejércitos y las leyes injustas. Por eso no es sorprendente que el proletariado de todo el mundo saluda a la Revolución Rusa y la admira. (Citado por Korolev y Kudachkin 1986, 21)

La poesía rusa estaba muy sensible a esta percepción de la revolución mundial. Un "soñador ucraniano", un muchacho, protagonista de los versos de Mijail Svetlov, "Grenada" (1926), en la guerra civil de 1918-1923 se unió al Ejército Rojo para luchar no solamente por la Revolución Rusa, sino que además por una causa mayor, sin saber muy bien siquiera dónde estaba España:

Abandoné mi choza, me fui a combatir,

Para entregar en Grenada la tierra a los campesinos

¡Adiós, familia, adiós, amigos

Grenada, Grenada, Grenada mía! ${ }^{8}$

Octubre de 1917 marcó profundamente la postura de los líderes obreros y socialistas que ya actuaban en América Latina. Hemos visto las expresiones del fundador del Partido Obrero Socialista de Chile, Luis Emilio Recabarren, que aceptó y celebró el triunfo de la Revolución. En 1922 viajó a Moscú para participar en el II Congreso del Komintern, declaró la transformación de su partido al comunista y su adhesión a la III Internacional. El líder del movimiento universitario de Cuba, uno de los fundadores del Partido Comunista de Cuba en 1925, Julio Antonio Mella, inspirado por la reforma universitaria de Córdoba, Argentina, en 1918, también experimentó una fuerte influencia de

${ }^{8}$ Se trata de la provincia de Granada, en el sur de España, cuyo nombre normativo, al igual que el de la ciudad, en el siglo XIX, se pronunciaba como Grenada. 
la revolución leninista, con su espíritu internacional y antiimperialista. Otra vez, en el imaginario colectivo la juventud cubana se adelantaba al conocimiento y racionalización. Como sostenía el futuro revolucionario José Martínez Sáez: "Nos deslumbraban la sencillez y la claridad aparentes de las teorías marxistas... todos los problemas cubanos podían explicarse por medio de la lucha de clases y el imperialismo yanqui" (citado en Aguilar 1992, 235).

Claramente, José Carlos Mariátegui, uno de los pensadores marxistas de Latinoamérica, no podía estar sino bajo el fuerte impacto de la revolución bolchevique. En 1922, durante uno de los momentos más álgidos de la Revolución Rusa, él estaba en Europa, casi en la frontera con Rusia. Anhelaba viajar al país de Lenin, pero no pudo por razones de salud. Participó en la formación del Partido Socialista de Perú en 1928, simpatizante con la III Internacional, pero su interpretación de la "realidad peruana", con su énfasis en una revolución inminentemente socialista, que incorporara también los elementos del comunitarismo campesino e indígena, trasgredía los límites del marxismo ortodoxo del Komintern y no podía ser aceptada; mientras que, por otra parte, el aparato de la III Internacional producía otro tipo de intelectuales, como el argentino Vittorio Codovilla, jefe del Comisariado (Buró) Iberoamericano del Komintern en Buenos Aires, conocido por su lealtad incondicional a los dictámenes que llegaban desde Moscú.

Durante los años 20, los líderes y la prensa de la izquierda latinoamericana aceptaban plenamente la representación de la sociedad socialista como resultado de la destrucción total del mundo burgués y de la construcción de un universo distinto. Por esta razón, la imagen de Rusia que aparecía en las páginas de diarios comunistas fue en todo diferente al mundo que rodeaba a los trabajadores de Latinoamérica: diferente en la organización económica, en los fundamentos políticos, en el modo de vestirse de la gente, en sus modales, lenguaje, estilo de vida. La influencia que tenía la Revolución Rusa sobre los líderes socialistas y la clase trabajadora de América Latina dejaba una huella realmente profunda. En 1923, Recabarren escribió:

...Queda demostrado que toda la población trabajadora es la dueña del poder desde el momento que en sus manos está elegir los elementos de poder y en sus manos está anular el poder... En Rusia es una realidad, una verdadera realidad que el pueblo elige 
sus administradores, en Rusia es una verdadera realidad que el pueblo tiene derechos electorales. (Citado por Lowy 2007, 93)

Las fuerzas que los pueblos de Cuba, Bolivia, Chile, El Salvador percibían como enemigas - miseria, "burguesía aborrecible", policía, "empresarios... los que me hicieron llevar piedras a la construcción del Vaticano moscovita" (Vergara 2013, 70) — en Rusia ya no existían aparentemente, creando en el imaginario de la izquierda latinoamericana la idea de que se creaba otra cultura, otra civilización, las cuales no solamente eran nuevas, sino que, además, pertenecían al pueblo.

No se trataba necesariamente de la democracia o de la lucha por ésta. Para la mayoría de los revolucionarios de esta época, la democracia no era un valor en sí; ella se asociaba con el poder de los pocos, con la oligarquía, con la comodidad de la burguesía, con la hipocresía y opresión, con el capitalismo. Y como el capitalismo y la burguesía tendrían que ser derrumbados, la democracia debía ser derrumbada también.

El mito de Rusia se construía en el contraste con la realidad de los países latinoamericanos; esto es, todos los males sociales que caracterizaban a la sociedad capitalista se creían estar resueltos en el lejano país revolucionario: la liberación de la mujer encarnaba la nueva moral y libertad; el acceso al arte simbolizaba la nueva cultura obrera y la nueva dignidad humana; el privilegio de la educación para los hijos de obreros era la causa justa, y la discriminación a la burguesía era símbolo de un castigo merecido, de igualdad y de restablecimiento de esa justicia social que durante tanto tiempo había sido violentada. Más tarde, en "Defensa del marxismo", de 1936, Mariátegui se refería a la Revolución de Octubre como "el primer paso de la humanidad para establecer el sistema de fraternidad, paz y justicia" (citado en Korolev y Kudachkin 1986, 20). Con el pasar de pocos años, en casi todos países de América Latina se fundaron partidos comunistas, la mayoría de los cuales se adhirieron a la Internacional Comunista. Así, surgió el Partido Comunista de Argentina en 1918, el de México en 1919, el de Uruguay en 1920, los de Chile y Brasil en 1922, entre otros. Pronto el fenómeno revolucionario soviético adquirió una dimensión realmente global: "Al cabo de treinta años de la llegada de Lenin a la estación de Finlandia, un tercio de la humanidad y todos los gobiernos entre el Elba y el mar de China vivían bajo el dominio de partidos comunistas" (Hobsbawm 2003, 125). 
La influencia de la experiencia soviética era más real todavía si consideramos que había cierta ingenuidad en el idealismo y romanticismo que profesaban varios comunistas, socialistas y anarquistas latinoamericanos hacia la Rusia comunista. Ello se juntó con que fueron obligados a mirar a la primera sociedad socialista a través de un prisma específico, prisma mediante el cual los líderes del Komintern les mostraban la "realidad" soviética a sus afiliados extranjeros durante sus visitas a la Rusia de los soviets. El emigrante ruso en Argentina M. Komin-Alexandrovsky, delegado argentino al II Congreso de la Internacional Comunista, describía sus impresiones sobre la Rusia Soviética de 1921:

La intensificación de la producción en la Rusia soviética no se obtiene con la ayuda del garrote y de la violencia de un explotador, sino desarrollando entre los obreros la conciencia de sí mismos y la autodisciplina. Ningún otro país puede suministrar un ejemplo semejante. Este cambio psicológico en los obreros es únicamente posible en un Estado proletario y obra verdaderos milagros, estableciendo nuevos récords en la producción... (Citado en Tarcus 2017, 39)

El sindicalista Augusto Pellegrini, en su informe "Mi viaje a la $\mathrm{Ru}$ sia de los Soviets", de 1923, compara la realidad rusa y la situación en Argentina:

Mientras en nuestros países nos niegan el derecho de organización, allí ésta casi tiene casi fuerza de ley, y mientras en los países burgueses la policía, el ejército combaten, persiguen y destruyen las fuerzas del proletariado organizado, allí son la mejor garantía de su vida. (...) ¡Todo en Rusia es libertad, derecho, justicia y hasta privilegio para los productores! (Citado en Tarcus 2017, 99)

Como sostenía François Furet, la devoción por la Revolución de Octubre que sentían varios comunistas de América y Europa se debía también a su incapacidad de componer una opinión racional sobre algo que no tenía precedentes (Furet 1996, 114). No es casual que la palabra "milagro" sea una de las más frecuentes que encontramos en varios textos periodísticos, políticos o poéticos que se referían a la Rusia revo- 
lucionaria. No se hablaba mucho sobre la ausencia de libertad, sobre la desnutrición de los niños o la violencia en contra de los reales o supuestos "enemigos de la revolución" (sólo André Gide se atrevió a hablar públicamente sobre el "lado oscuro" de la idealizada realidad soviética). El brillo de la promesa de una vida justa y mejor hacía ciegos a los que la esperaban.

Por otra parte, en las décadas de los 20 y 30, incluso en los sectores más conservadores de las sociedades latinoamericanas, creció el interés (y no solamente el temor) al "experimento soviético". Tras el repudio inicial y la condena a la violencia y destrucción de la Rusia antigua, los observadores del campo opuesto al de los bolcheviques comenzaron a concentrar su mirada en los aspectos morales y culturales de la revolución leninista. Se puso atención a los problemas del arte, la cultura, el teatro y las políticas educacionales del Estado soviético. Los círculos católicos se interesaron por las innovaciones que los bolcheviques incorporaron en la legislación familiar, cuidado de los hijos, constitución matrimonial, distribución de responsabilidades en la educación de los niños y el papel y el lugar de la mujer en la sociedad. Aparecieron interesantes publicaciones que proponían una mirada más profunda sobre el movimiento de octubre de 1917, que seguía la línea filosófica de análisis de la revolución que desarrollaron los filósofos rusos Berdiáyev, Losev y Fedotov.

Para varios de estos autores (rusos y latinoamericanos), la revolución bolchevique no fue una ruptura, sino un hecho propio $-\mathrm{y}$ hasta de continuidad - de la historia de Rusia, haciendo ciertos paralelos entre el marxismo soviético y la identidad nacional rusa. En este aspecto, la ideología del régimen soviético se presentaba como la continuación de la gran tradición cristiana ortodoxa, reemplazada por la ideología marxista:

El carácter fundamental del bolchevismo es una religión nueva, que toma en serio las tendencias modernas de la política y la economía como las cosas que dan sentido a la vida y reviste estas tendencias de exigencias éticas y de promesas para el futuro. ${ }^{9}$

Según esta visión, después de la destrucción de los templos, en Rusia se creó otro tipo de religión: la "fe" marxista, con su simbología

${ }^{9}$ El Diario Ilustrado, 23 de agosto de 1933. 
laica de templos - edificios del partido-, himnos y banderas, rituales y fiestas sagradas - el 1 de mayo, el 8 de marzo, el Día de la Revolución el 7 de noviembre, el Día de Cumpleaños de Lenin el 22 de abril-. Esto se complementa con el "reino milenario" comunista y la adoración al cuerpo de Lenin, el cual, embalsamado, canonizado, fue puesto en el mausoleo sin enterrar; o, también, con la devoción a nuevos ídolos y mártires -Espartaco, jacobinos, líderes de las rebeliones campesinas rusas del siglo XVIII, héroes de la Comuna de París y de la guerra civil de la década de 1920 - y con la devoción a los discursos basados en los libros "infalibles": El capital, de Karl Marx, obras de Lenin y Stalin. Más tarde lo confirmaba Nikolái Berdiáyev:

La causa del dinamismo único y eficiencia del marxismo consiste en el hecho de que contiene en sí todas las características de una religión. (...) El marxismo ha sido adaptado a las condiciones rusas y ha sido rusificado. La idea mesiánica del marxismo vinculada con la misión del proletariado se vinculaba y se identificaba con la idea mesiánica rusa. (Berdiáyev 1990, 305).

Esta idea nos lleva a un aspecto que no siempre es considerado por los historiadores de la revolución y de las ideologías, incluidos aquellos que estudian el impacto que tuvo la revolución bolchevique en el mundo y en América Latina.

Nos parece importante recalcar el rol de los intelectuales en los procesos revolucionarios del mundo (lo que, por cierto, no es algo nuevo en los estudios de las revoluciones). Es bien sabido que tanto en Rusia como en Europa y América Latina muchos intelectuales apoyaron la revolución bolchevique y militaban en partidos comunistas de sus respectivos países. Romain Rolland, Henry Barbusse, Pablo Picasso, Eric Hobsbawm, en Europa; Máximo Gorki, Alexandr Blok, Vladímir Mayakovski, Sergei Esenin, en Rusia; los muralistas Siqueiros y Rivera, los escritores Jorge Amado, Gabriel García Márquez, Pablo Neruda, en América Latina, son sólo algunos ejemplos de los estrechos vínculos que existían entre la intelectualidad artística y académica con el comunismo.

En este sentido, es interesante llamar la atención a las palabras de Marta Vergara que citamos arriba sobre la construcción del "Vaticano moscovita". Desde nuestra perspectiva, existe una gran coincidencia 
entre la intelligentsia revolucionaria de Rusia y los intelectuales comunistas de América Latina. Ambos grupos tenían un importante componente religioso, hijos, como eran, de una poderosa cultura cristiana, una ortodoxa y la otra, católica. Elementos de la cultura católica latinoamericana se combinaban con la religiosidad y misticismo del pueblo ruso y el sentido mesiánico de la revolución. Ambos movimientos sentían la vocación mesiánica de salvación y redención, dispuestos a ser crucificados ellos mismos para crear el reino de Dios ahora y en esta tierra.

Así describía el filósofo Nikolái Berdiáyev el carácter religioso del comunismo ruso: "El alma rusa se está quemando en búsqueda ardiente de la verdad, de la verdad absoluta y divina y de salvación de todo el mundo y de la resurrección común hacia la nueva vida" (Berdiáyev 1990, 105). El universalismo del comunismo ruso se debe a su conciencia mesiánica: "La conciencia mesiánica no es nacionalista... Es la conciencia universal. La conciencia mesiánica es la conciencia del pueblo escogido de Dios, en el cual el Mesías tiene que aparecer, y a través del cual el mundo deberá ser salvado" (Berdiáyev 1990, 105). Sin entender el carácter mesiánico de la Rusia comunista, no se puede entender la fuerza con la cual el mundo (tanto el de izquierda como el de derecha) fue absorbido por la idea de la revolución proletaria internacional.

Es importante llamar la atención sobre el hecho de que la "Revolución Rusa", de octubre de 1917, nunca tuvo objetivos ni carácter nacional. Como bien señala Orlando Figes (2008), los líderes de esta revolución no se sentían necesariamente rusos. No solamente por la mezcla de los genes étnicos alemanes, suecos, judíos, rusos, mordvines que tenían en su sangre, sino que también porque eran personas cosmopolitas, ciudadanos del mundo que hablaban varios idiomas europeos, vivieron en distintas partes de Europa por años, conocían a los líderes de la II Internacional y siempre percibían a la revolución proletaria como un acontecimiento universal. Para ellos, la revolución socialista no tenía patria ni nacionalidad — según sostenía el propio Karl Marx, "el proletariado no tiene patria"- , y, consecuentemente, la Revolución de Octubre inmediatamente debería ser seguida por la revolución paneuropea $y$, después, por la mundial. América Latina ha sido incorporada desde un principio a este proyecto global, y los sectores socialistas, anarquistas, maximalistas que ya existían en la región rápidamente se convirtieron en receptores de una importante producción propagandística, educativa 
e informativa de la Internacional Comunista. En el documento llamado "El deber del proletariado de América del Sur", de 1922, los líderes del Komintern llamaban:

Como en la Revolución Rusa, os prepararéis para transformar cualquier intento de guerra en lucha abierta de la clase obrera contra la burguesía. Como ella, llevaréis a cabo la acción contra el imperialismo preparando la dictadura proletaria que destruirá en toda América la dictadura burguesa. (Lowy 2007, 90)

Este fenómeno se replicaba en el mesianismo revolucionario de los comunistas latinoamericanos. Como sostenía Carlos Fuentes, ellos también eran:

los hijos de rígidas sociedades eclesiásticas. Ésta era carga de América Latina, pasar de una iglesia a otra, del catolicismo al marxismo, con todo su dogma y ritual. El comunismo, al igual que el catolicismo, representaba una fe universal y total. Moscú sustituyó a Roma como dogma e inspiración. (Citado por Bethell 1997, 78)

Y los partidos comunistas de todo el mundo, integrantes de la Internacional Comunista, estaban unidos por esta conciencia mesiánica de salvación, de pertenencia a un fenómeno global que tenía un propósito sagradamente digno: salvar a la humanidad del capitalismo y hacerla mejor y feliz. Este sentimiento de participación en un movimiento desinteresado y universal, quizás, explicaba la absoluta e incondicional lealtad que profesaban muchos de los comunistas europeos hacia la URSS, sin importar el terror estalinista ni la hipocresía y decadencia del "socialismo real": "Hasta en los peores momentos, aun rechazados o víctimas de sospechas injustas (estos comunistas no podían concebir otra existencia que servir a la causa de Octubre del 1917), como si allí hubiese nacido en verdad el otro mundo" (Furet 1996, 123).

Pero también el mundo comunista del siglo XX sería imposible de comprender sin considerar esta sensación de pertenencia a "un movimiento global, cosmopolita y omnipresente de ser redentores del mundo entero..." (Ulianova y Riquelme 2005, 93). Al mismo tiempo, quizás este reconocimiento a Moscú como Vaticano del movimiento comu- 
nista internacional provocaba el hecho de que los partidos comunistas latinoamericanos percibieran como algo natural y lógico que el "centro jerárquico" comunista proporcionase el financiamiento para sus "parroquias anticlericales" y sus publicaciones, sin cuestionamiento alguno (Ulianova y Riquelme 2005, 42).

El mundo nuevo requería también al otro tipo de hombre, al "hombre nuevo": un hombre (y mujer, por cierto) que tenía que ser totalmente abnegado y dedicado a la causa de la salvación de la humanidad, a la revolución; un hombre absolutamente comprometido con el partido; un hombre que debía ser, de hecho, un monje, un puritano que rechazaba la vida cotidiana, la familia, las "debilidades" humanas, para que no lo distrajesen de los fines de la revolución. "El Partido se anteponía a todo lo personal" (Hobsbawm 2003, 132).

Un verdadero revolucionario tenía que rechazar toda vida individual, pues su existencia pertenecía a la causa colectiva. Debía ser coherente, íntegro, austero, bondadoso, leal. ${ }^{10}$ Una de las imágenes más impactantes del revolucionario de este tipo fue Rajmetov, quien rechazaba los "sentimentalismos" y el amor (y hasta dormía en un lecho de clavos puntas arriba, preparándose para eventuales torturas). Él era uno de los protagonistas de la fundacional novela de Nikolái Chernyshevski ¿Qué hacer? (1863), favorita de Vladimir Lenin. Más tarde, en las décadas de los 50 y 60 , en muchos países latinoamericanos la imagen de la dedicación y del sacrificio por la causa justa, del martirologio por los fines sublimes, aparece al publicarse la traducción al español de una de las obras icónicas de la literatura revolucionaria soviética, la novela de Nikolái Ostrovski Así se templó el acero (1932), cuyo personaje central, Pavka Korchaguin — quien, a pesar del dolor y de una posible pérdida de movilidad debido a las heridas recibidas en la guerra civil, se levantaba y seguía levantándose para ir a trabajar por el deber que sentía frente a la revolución-, se convirtió en el modelo a seguir para miles de jóvenes latinoamericanos encantados por la Revolución Rusa, la $\mathrm{Cu}$ bana y la figura de Ernesto Che Guevara.

No es casual que el "código moral del constructor del comunismo" de la Unión Soviética replicaba casi literalmente al decálogo de Moisés.

${ }^{10}$ No estamos hablando de los apparatchiki del Comité Central del PCUS o de los burócratas del Secretariado Sudamericano del Komintern, acostumbrados a los viajes all inclusive a Moscú. 
"En Rusia no puede ser cualquiera afiliado al partido" (Tarcus 2017, 137): el verdadero comunista tenía que ser no hablador, sino sensato y parco, justo y ecuánime, abnegado y afable. No un vividor, sino honrado, desinteresado, ordenado y sobrio. Escribía un veinteañero comunista, el futuro historiador británico Eric Hobsbawm:

La libertad, la igualdad y sobre todo la fraternidad pueden hacerse realidad momentáneamente en aquellos estadios de las grandes revoluciones sociales que las revoluciones que las vivieron describen en términos normalmente reservados al romanticismo. Los revolucionarios no sólo se imponen un modelo de moralidad más elevado que el de cualquier santo sin excepción, sino que cuando llega el momento realmente lo llevan a la práctica... (Hobsbawm 2003, 133)

Un partido constituido por personas de este perfil no podía ser un partido de masas. Tenía que ser un grupo cerrado, una subcultura aparte, con sus propios códigos éticos, de lenguaje y de comportamiento, lo que creaba un sentimiento de pertenencia a la elite que conocía la "única y absoluta verdad". Sus militantes "sabían" cómo tenía que ser el futuro. Como plantea Hobsbawm, el "partido de vanguardia leninista era una combinación de disciplina, eficiencia en el trabajo, absoluta identificación emocional y un sentido de dedicación total" (Hobsbawm 2003, 130). Además, el autosacrificio sin recompensa alguna ya estaba en su misión redentora de salvación: desde la muerte y el exilio de los decembristas de Rusia, los revolucionarios posteriores sabían que los esperaban la persecución, el destierro, la soledad, la cárcel, la tortura o la ejecución. La izquierda europea y latinoamericana ganó el respeto de sus sociedades no por seguir las indicaciones de la Unión Soviética, sino por su estoicismo y lealtad a los ideales, sin pedir nada a cambio.

Por otra parte, el modelo leninista del partido revolucionario revirtió toda la teoría de la revolución socialista de Karl Marx, al mismo tiempo que provocó la pregunta sobre la aplicabilidad del marxismo al contexto latinoamericano. La teoría marxista de la revolución socialista suponía que, para darse la situación revolucionaria, un país debería poseer un alto desarrollo económico e industrial, donde el conflicto social se produciría a raíz de las contradicciones internas del desarrollo capitalista. Ahora, como mostró la experiencia del partido de Lenin, teniendo 
un partido pequeño con el liderazgo fuerte, sumamente disciplinado, unificado, convencido de poseer "la verdad absoluta" y dispuesto a pagar cualquier costo (propio o externo) para imponer esta verdad al resto de la humanidad, no era necesario esperar la "maduración del capitalismo". El modelo leninista parecía ser mucho más eficiente y operativo. Por cierto, el marxismo era una teoría europea por definición. Pero el atractivo del bolchevismo para los líderes obreros y campesinos de América Latina consistía justamente en eso: en Rusia, un país atrasado y de población mayoritariamente campesina, el partido bolchevique se atrevió a tomar el poder, para pasar inmediatamente a la construcción del socialismo, convirtiendo una sociedad semifeudal o colonial en una socialista, industrializada y desafiante al capitalismo. O sea, un pequeño grupo de personas cohesionadas, provisto de liderazgo fuerte y convicciones sólidas se mostró capaz de "mover las montañas". Entonces, en América Latina la revolución socialista también era posible, sin que su fuerza hegemónica tuviese el apoyo de las masas.

Había factores que explicaban por qué un partido marxista leninista no podría encontrar el apoyo masivo en la mayor parte de las sociedades latinoamericanas. Una revolución del proletariado y para el proletariado difícilmente podría encontrar la base masiva en los países donde la clase obrera estaba recién en proceso de formación. Las condiciones de dependencia colonial, de dependencia económica, de subdesarrollo no permitían plantear la posibilidad de una "revolución socialista" masiva en Sudamérica y en el Caribe. También influían otros factores, como el predominio de los trabajadores de los sectores artesanos y rurales por sobre los obreros organizados, la fuerte competencia del catolicismo, fuertes represalias contra los simpatizantes de la izquierda, existencia (como en Perú, Bolivia, Argentina) de otros partidos políticos, populistas y nacionalistas, que, a diferencia de los partidos comunistas, no eran tan rígidos y eran más flexibles en sus alianzas, y, por cierto, los esfuerzos del aparato de Estado por incorporar a los sindicatos al sistema estatal a fin de controlarlos (Angell 1997, 79). Al menos desde la estrategia de formación de Frentes Populares (1935), los partidos comunistas de América Latina aceptaron los dictámenes del Komintern, que de hecho replicaban el programa de los mencheviques para Rusia antes del 1917: no tomar el poder político de inmediato, sino que formar las coaliciones políticas con los gobiernos y actores políticos moderados en espera de la maduración del capitalismo en sus respectivos países, 
el aumento del nivel de desarrollo y la formación de la estructura económica y social para la formación de la clase obrera, consciente y lista para llevar a cabo la revolución, pero no socialista, sino que la revolución burguesa y democrática. La socialista debería esperar aún más.

Sin embargo, como hemos dicho, el impacto de la Revolución de Octubre iba más allá de los debates teóricos entre los comunistas latinoamericanos, y entre ellos y las autoridades del Komintern. Los pueblos latinoamericanos percibían lo sucedido en Rusia a nivel emocional. El imaginario colectivo producía mayor efecto que las ideologías racionales. Por poco que supieran sobre Rusia, les parecía cercana por ser un país campesino, pobre, atrasado, donde la mayoría de la población vivía en humillación, miseria, dependencia económica y personal de un poderoso. Así describía la situación social en El Salvador del 1932 el mayor estadounidense A.R. Harris, agregado militar de EE.UU. para América Latina: "Imagino que la situación de El Salvador hoy es bastante parecida a la de Francia antes de la revolución, a la de Rusia antes de la revolución y a la de México antes de la revolución. La situación está madura para el comunismo, y los comunistas parecen haber descubierto eso" (Lowy 2007, 22).

Pese a que varios partidos comunistas de América Latina se adhirieron tempranamente a la Internacional Comunista, los líderes del Komintern no creían que la revolución en Latinoamérica podría anteceder a una revolución socialista en Europa (Angell 1997, 81). No tenían mucho conocimiento sobre los problemas vitales del continente, como el problema del campesinado, la desigualdad, la situación indígena. No era la política de la Unión Soviética hacia América Latina, ni la labor de los comisarios de la Internacional Comunista ni el programa de insurrección comunista los que hacían sublevarse a los salvadoreños en 1932, a los cubanos en 1933 y 1959 o a los guatemaltecos en 1952. En el caso de la rebelión en El Salvador, tan fuerte había sido el impacto del espíritu revolucionario del proletariado ruso que en este país caribeño, donde casi no existía el proletariado, los rebeldes campesinos constituyeron igualmente los "soviets" con el fin de llevar a cabo la revolución socialista (Angell 1997, 81). En el imaginario de los mineros, trabajadores ferroviarios y textiles del Cono Sur, azucareros y cafeteros de América Central, la visión de Rusia revolucionaria seguía siendo muy romántica e idealizada. El triunfo de los bolcheviques y la Revolución Rusa eran símbolos, sueños pero casi nunca la realidad concreta. 
En 1918, el legendario poeta ruso Aleksandr Blok escribe su famoso poema revolucionario "Doce". Es la elaboración de un verso trágico y nervioso, en el que describe la marcha de los doce guardias rojos por las calles de Petrogrado, ${ }^{11}$ observando los cambios y dramas que acompañaban la Revolución. Los soldados son presentados como "apóstoles" del pueblo revolucionario, con sus miedos, dolores y alegrías, con sus esperanzas y victorias enarboladas en sus fusiles y banderas rojas. Esta marcha es liderada por la figura de un revolucionario eterno: Jesucristo, que va adelante coronado de rosas blancas. Los mismos motivos encontramos en el poema del iquiqueño Daniel de la Vega, quien en 1922 escribe, dirigiéndose a Rusia:

A su encuentro Jesús vendrá en breve

Como un rosal luminoso y humano

Entre la sombra y el hambre y la nieve

Florecerá el corazón tolstoyano. (...)

Anda tú hacia ella, ruda flauta mía

Y con tu alabado de ardiente supremos

De la que aquí estamos aguardando el día

Y que en avalancha nos levantaremos. ${ }^{12}$

Sin tener la posibilidad de conocer el país, la Unión Soviética, de tan remota, les parecía una tierra prometida para los olvidados e invisibles. Así, por ejemplo, en medio del gran terror estalinista, un poeta antofagastino (que seguramente no tenía mucha información sobre qué es lo que pasaba en la URSS) escribía en su poema:

Así llegaste a Rusia. Ardiente y vencedora

Revolución de Octubre.

Atravesando el cielo rojo de la vida

Habitando en la esperanza más alta de las multitudes

Asomándote el corazón castigado y generoso de los pobres

Barriendo las fronteras y uniendo en un solo puño

Las manos caídas y confusas de los explotados. ${ }^{13}$

${ }^{11}$ Petrogrado es el nombre que tuvo San Petersburgo entre 1914 y 1924, antes de llamarse Leningrado (N. del E.).

${ }^{12}$ El Despertar de los Trabajadores, 2 de abril de 1922.

${ }^{13}$ El Frente Popular, 1 de diciembre de 1937. 
Como es bien sabido, el segundo mito fundacional más importante en la historia de la Unión Soviética, después de la Revolución de Octubre, es la victoria de la URSS sobre la Alemania nazi en la Gran Guerra Patria (que es como en Rusia se conoce a la Segunda Guerra Mundial). Y para muchas personas soviéticas, para la izquierda del mundo y de América Latina esta victoria ha sido resultado, continuación y consolidación de la Revolución de 1917. Sin la Revolución de Octubre, esta victoria hubiera sido imposible, pues en el imaginario colectivo de izquierda el socialismo triunfó sobre el nazismo (y el heroísmo del pueblo soviético, por tanto, también era socialista). Como tal, esta victoria no podía ser interpretada de una manera del todo racional, sino que como algo que provenía de otro mundo, heroico y sublime. Escribe Pablo Neruda en su "Tercer canto de amor a Stalingrado", poema sobre el triunfo de los soviéticos en la batalla por esta ciudad:
¡Oh! Milagros
Milagros de la sangre
Milagros de acero y de Partido
Milagros de nuestro nuevo mundo.

(Neruda 1954, 35)

Volvemos a plantear que el principal impulso a los intentos revolucionarios de América Latina no fue tanto el comunismo en sí como el hecho propio del triunfo de la revolución bolchevique. Este triunfo pudo prometer que las "manos caídas" podían levantarse, ofreciéndoles por primera vez a los pobres del mundo la alternatividad, la promesa de que la victoria era posible. Por primera vez en la historia del mundo para los "explotados" latinoamericanos aparecía una opción de vida y desarrollo: la alternativa socialista que se establecía en el país más pobre de Europa; la alternativa que podía convertir a este país en uno de los más poderosos del mundo y cuya ideología, enfrentada al capitalismo, se expandía rápidamente por todo el universo (Maidanik 1998, 39). El impulso de la revolución bolchevique permitió a miles de latinoamericanos atreverse a levantarse contra los "malditos problemas de la época" e intentar salir de la miseria, la humillación y la obediencia. Este mismo espíritu inspiró más tarde a los movimientos por la descolonización y por la liberación nacional. Obviamente, la misma alternatividad les daba prestigio y respeto a los miembros de los partidos comunistas 
en sus respectivos países latinoamericanos: eran parte coherente y comprometida de una fuerza universal (la revolución bolchevique), cuyo objetivo consistía en salvar a los oprimidos de la opresión. Así también, no fue la teoría leninista de la formación del partido y de la toma del poder, sino que la espiritualidad revolucionaria y la promesa de empoderar a las masas pobres y antaño "invisibles” aquello que inspiró más tarde a los pensadores de la "teología de liberación".

Pero la Revolución de Octubre tuvo su "espejo". Sin lugar a dudas, otra revolución que mostró una enorme importancia para América Latina y para el mundo en general fue la Cubana. Es curioso que los comunistas cubanos no reconocieran a la revolución en el momento de su estallido, tal como los bolcheviques no vieron venir la explosiva Revolución de Febrero de 1917. Es curioso que el movimiento 26 de Julio, no necesariamente marxista o comunista en su origen y tampoco dirigido desde la Unión Soviética, dado el contexto de la Guerra Fría, haya sido rápidamente reconocido como una "victoria del comunismo". Y es curioso, por lo tanto, que el mismo contexto de la confrontación bipolar entre la URSS y Estados Unidos hiciera a Fidel Castro declarar en Moscú en 1963 que "sin la Revolución de Octubre la Revolución Cubana no fuese posible" (Castro 1963).

No es nuestra intención analizar el impacto que tuvo en América Latina la entrada de los "barbudos" a La Habana en enero del 1959. Nos parece importante, sí, llamar la atención sobre la influencia recíproca que tuvo la revolución caribeña en la sociedad soviética, que ya estaba cansada de tantas promesas de la llegada pronta del comunismo, de las represalias estalinistas, de la guerra y del trabajo a puro entusiasmo. La sociedad de la URSS salía de un terrible período de terror estalinista, que dejó a toda la gente soviética en confusión, preguntando por qué una revolución con fines tan sublimes y demandas éticas tan elevadas terminaba con tantas muertes, campos de concentración y la formación de una "cultura del terror". Nadie en la Unión Soviética sabía mucho sobre Cuba, pero su revolución despertó en la juventud soviética nuevas esperanzas de que volviera la pureza y la sinceridad a los líderes revolucionarios, ya que, como dijeron los escritores disidentes soviéticos Petr Vayl y Aleksandr Genis, se creía "en su carácter honesto y poético" $(2013,34)$.

Según nos contaban nuestros profesores, en 1959, al recibirse la noticia de la caía del régimen de Batista, se desató una fiesta y un ver- 
dadero carnaval estudiantil en las aulas de la Universidad Lomonosov de Moscú. En la sociedad soviética, donde la ilusión sobre la cercanía de la revolución mundial comenzaba a desvanecerse, la victoria de Castro y el Che Guevara sirvió como un ejemplo perfecto para demostrar que el Partido Comunista de la URSS tenía razón, que la revolución mundial ya venía y podía triunfar, si no en Europa, sí en el Tercer Mundo. Así reflexionaban los ex estudiantes soviéticos de los 60: "La Revolución Cubana se convirtió fácilmente en la metáfora de la Revolución de Octubre, porque el golpe revolucionario en sí fue sometido a las leyes del arte y de la dialéctica. Triunfó el Hombre Nuevo creado por la Revolución" (Maidanik 1998, 56).

Posteriormente, todo intento revolucionario en América Latina —Chile en 1970, Nicaragua en 1979 - fue utilizado por el PCUS para objetivos internos, con el fin de mantener en los jóvenes la fe en la revolución proletaria global. Sin embargo, estos acontecimientos nunca tuvieron en la URSS un impacto tan importante como el que tuvo la Revolución Cubana. Ésta tampoco cumplió su promesa: con el pasar de los años y en la medida en que se ligaban entre sí el gobierno de la Unión Soviética y el cubano ya declarado marxista, en la medida en que aumentaba la crisis alimentaria en la URSS, mientras Moscú seguía proporcionando ayuda a Cuba, en la sociedad soviética volvieron a surgir sospechas sobre la pureza de la revolución y la sinceridad de sus líderes, hasta desarrollar una fuerte desconfianza del sistema político cubano y una decepción respecto a que Cuba podría haber revivido los ideales de la Revolución de Octubre de 1917.

¿Cuál fue la importancia y sentido de la Revolución Rusa? ¿Califica como una catástrofe que costó millones de vidas y que acabó con la milenaria cultura de Rusia? ¿O efectivamente constituyó una promesa de salvación, liberación y construcción de una sociedad justa y fraternal? No podemos dar ahora una respuesta definitiva. Como sostienen algunos historiadores, todavía ha transcurrido muy poco tiempo para formular el juicio consensuado y definitivo sobre el sentido verdadero de la revolución bolchevique. Pero nos parece que efectivamente la Revolución de Octubre hizo su aporte para el mundo.

Como dijo Furet, su proyecto era atractivo. En el mundo capitalista de principios del siglo XX, la idea de la igualdad y justicia social ganó inmediatamente popularidad e interés, tanto en círculos obreros, como 
entre los intelectuales. La Rusia soviética ofreció al mundo un experimento de ingeniería social que no tenía precedentes en la historia de la humanidad. Y esta promesa de erradicar la desigualdad, acabar con la pobreza y explotación, fue escuchada en América Latina con una atención especial.

La Revolución de Octubre, basada en la idea de la igualdad de todas las naciones, dio un enorme impulso a los pueblos colonizados para comenzar la lucha contra el colonialismo y la independencia nacional. La Revolución de Octubre abrió los canales de una movilidad social jamás antes vista en la historia del mundo, abriendo posibilidades para la educación, cultura, participación, reconocimiento, visibilidad ciudadana para los millones de personas que habían sido privadas de estos derechos civiles durante siglos. El costo de estas aperturas fue altísimo, y no es casual que las visiones críticas que expresaban Rosa Luxemburgo o Antonio Gramsci hacia las políticas leninistas fueran silenciadas.

Sin embargo, es importante considerar que ya a mediados del siglo XX varios intelectuales de izquierda aclaraban las diferencias entre la Revolución de Octubre y la realidad de la Unión Soviética. Muchos intelectuales y personeros políticos, como André Gide, Eric Hobsbawm y Ernesto Guevara, viajaron a la URSS. Pero la realidad de una sociedad que pretendía ser la "alternativa al Primer Mundo" no correspondió a sus expectativas en absoluto. El "primer país socialista" no era lo que prometía la Revolución de 1917. La promesa de construir un mundo justo y feliz, donde el poder perteneciera a los trabajadores, no se cumplió. Pero tan fuerte ha sido el impacto de la Revolución de Octubre, tan poderosa su imagen y tan atractivos sus principios éticos y sociales, que muchos comunistas han conservado lealtad a sus ideales de por vida, sin importar si mantuvieron su militancia en el partido o no, sin importar su desilusión con el estalinismo y la Unión Soviética. La promesa de la Revolución de Octubre era crear una sociedad de respeto al ser humano, de dignidad, igualdad social y apoyo mutuo entre los ciudadanos. Crear una sociedad de cercanía, confianza y fraternidad entre los prójimos. La promesa de la Revolución de 1917 fue mucho más que su resultado, la Unión Soviética, cuyo modelo económico y social al fin y al cabo no correspondió a los ideales de Octubre. 


\section{REFERENCIAS}

Aguilar, L. 1992. "Cuba, 1860-1934”. En Historia de América Latina, vol. 9. México, América Central y el Caribe, 1870-1930, editado por L. Bethell, 210239. Barcelona: Crítica.

Angell, A. 1997. "La izquierda en América Latina desde 1920". En Historia de América Latina, vol. 12. Política y sociedad desde 1930, editado por L. Bethell, 73-131. Barcelona: Crítica.

Bazco, B. 1984. Los imaginarios sociales. Memorias y esperanzas colectivas. Buenos Aires: Nueva Visión.

Berdiáyev, N. 1990. Sud'ba Rossii. Moscú: Sovetsky Pisatel.

Bethell, L., ed. 1992. Historia de América Latina, vol. 10. América del Sur 18701930. Barcelona: Crítica / Grijalbo / Mondadori.

— 1930.

Castañeda, J.C. 1994. La utopía desarmada. Intrigas, dilemas y promesas de la izquierda en América Latina. Buenos Aires: Ariel.

Castro, F. 1963. "Discurso pronunciado por el comandante Fidel Castro Ruz, Primer Secretario del Partido Unido de la Revolución Socialista y Primer Ministro del Gobierno Revolucionario, en la Plaza Roja de Moscú, en el gran acto de bienvenida que se le brinda a su llegada a Moscú, el 28 de abril de 1963". http://www.cuba.cu/gobierno/discursos/1963/esp/f280463e.html

Etkind, A. 1998. Jlyst. Sekty, literatura y revoliutzia. Moscú: Novoye literaturnoe obozreniye.

Figes, O. 2008. La Revolución Rusa (1891-1924). La tragedia del pueblo. Barcelona: Edhasa.

Furet, F. 1996. El pasado de una ilusión. Ensayo sobre la idea comunista del siglo $X X$. Ciudad de México: Fondo de Cultura Económica.

Hobsbawm, E. 2003. Años interesantes. Una vida del siglo XX. Buenos Aires: Crítica.

. 2007. Historia del siglo XX. Buenos Aires: Planeta.

Korolev, Y. \& M. Kudachkin. 1986. Latinskaya Amerika: revolyutzii XX veka. Moscú: Izd. Politicheskoy literatury.

Lowy, M. 2007. El marxismo en América Latina. Antología. Santiago: LOM.

Loyola, M. \& J. Rojas, comp. 2000. Por un rojo amanecer. Hacia la historia de los comunistas chilenos. Santiago: sin editorial.

Maidanik, K. 1998. "Ernesto Guevara y su época". En Svobodnaya Mysl, 38-50. Moscú: Pressa.

Neruda, P. 1954. Los versos más populares de Pablo Neruda, edición de cincuentenario. Santiago: Austral, 1954.

Quijano, A. 2007. "José Carlos Mariátegui: reencuentro y debate". Prólogo a Siete ensayos de interpretación de la realidad peruana, de J.C. Mariátegui. Caracas: Fundación Biblioteca Ayacucho. 
Tarcus, H. ed. 2017. Primeros viajeros al país de los Soviets. Crónicas porteñas 1920-1934. Buenos Aires: Buenos Aires.

Thomas, H. 2012. Cuba. La lucha por la libertad. Barcelona: DeBolsillo.

Ulianova, O. \& A. Riquelme. 2005. Chile en los archivos soviéticos, 1922-1991, tomo 1. Komintern y Chile, 1922-1931. Santiago: Dibam.

Varas, A. 1991. De la Komintern a la Perestroika: América Latina y la Unión Soviética. Santiago: Flacso.

Vayl, P. \& A. Genis A. 2013. 60-e. Mir sovetskogo cheloveka. Moscú: AST.

Vergara, M. 2013. Memorias de una mujer irreverente. Santiago: Catalonia. EP 
